PESHAWAR JOURNAL OF PSYCHOLOGY AND BEHAVIORAL SCIENCES, 2018, VOL. 4, NO. 2, 221-235

\title{
Emotional Climate, Work Stress and Occupational Cognitive Failure in Doctors
}

\author{
Shaukat Hussain , \\ Government Postgraduate College, Jhang \\ and \\ Iram Batool' ${ }^{2}$, \\ Bahauddin Zakariya University, Multan \\ Sheher Bano ${ }^{3}$ \\ Government Postgraduate College, Jhang
}

\begin{abstract}
Hina Ali ${ }^{4}$
Women University Multan

The current study was conducted to explore emotional climate, work stress and occupational cognitive failure among doctors. The sample of 150 doctors was selected from two cities of Pakistan i.e. Jhang and Faisalabad. Emotional climate was measured by Emotional climate scale by Yurtsever \& De Rivera (2010), for work stress, Work Place Stress Scale by American institute of stress and adapted by Fatima Chohan (2013) was used. Occupational Cognitive Failure was measured by occupational cognitive failure questionnaire by Allahyari, Rangi, Khosravi and Zayeri (2011) was used. Results revealed that Emotional climate, work stress and cognitive failure are significantly positively correlated. No significant difference between male and female, rural and urban, government and
\end{abstract}

\footnotetext{
${ }^{1}$ Lecturer, Department of Applied Psychology, Government Postgraduate College, Jhang

${ }^{2}$ Assistant Professor, Department of Applied Psychology, Bahauddin Zakariya University, Multan

${ }^{3}$ Lecturer, Department of Applied Psychology, Government Postgraduate College, Jhang

${ }^{4}$ Assistant Professor, Department of Economics, Women University Multan
}

ISSN 2415-6779 EISSN 2518-4474

https://doi.org/10.32879/picp.2018.4.2.221

www.pjpbsicp.com 
private doctors on the level of emotional climate, work stress and occupational cognitive failure was found. Significant difference between nuclear and joint family doctors on the level of work stress was found. Doctors from nuclear family system showed higher level of work stress as compared to Joint family doctors. Emotional climate, work stress and demographic variables are predictors which collectively and significantly contributed to occupational cognitive failure.

Keywords: emotional climate, work stress and occupational cognitive failure.

In recent era, the high job stress is considered the major cause for job change in employees. This job change affects individual well-being as well as cognitive abilities of employees. The high stress is assumed to be related with discrepancy in between employees job and its requirements. This mismatch intensifies stress at workplace and also affects the life of the employees. Employees are expected to be adjustable at workplace for changing environmental demands. The low level of job and employee fit leads to occupational cognitive failure, high level of stress and inefficient workplace behavior (Deniz, 2015). The emotional climates of the organization created by the policies of the organizations and the work stress have an impact on the cognitive functioning of the employees.

We all as human beings are emotional beings and this emotional being experience different emotions like hatred, anger, joy and love. Emotions are described as the feelings about self at conscious level about the objects in the environment and tags that humans assign to specific states of provocation from a cultural point of view (Turner, 2007). Emotions are experienced on constant basis. The perceived Emotional arousal might be either positive or negative for instance excitement or fear (Berggren, 2011). The Emotional climate refers predominant collective emotions as perceived and shared by all members of societal clustersjust like national community or ethnic minorities. De Rivera and Paez (2007) explained the emotional climate as predominant shared emotions engendered by the interaction of social group members in certain specific setting. The emotional climate of a certain organization includes its beliefs, attitudes, goals and values. Comprehensively the emotional climate is regarded as the perceived feelings of the majority members in an organization about the situation assembled by the organization. The debate 
encompassing the conceptions of organizational culture and climate is inconclusive. Culture is somewhat stable pattern while the climate is relatively temporary condition.

According to Cox, Griffiths and Rial-Gonzalez (2006) stress is a state of nervousness and uneasiness with the work, which have direct effect on employee emotions as well as physical health. Holmlund, Rytkonen and Strandvik, (2005) stated that Work stress is the lower level of the capacity to cover with work pressure and the wrong selection of the occupation and miss requirements of the work from the occupation. According to Greenberg, (1990) there are different factors which cause the stress reaction. These factors include psychological (threats to self-esteem, depression), biological (cold, toxins, heat), philosophical (use of time, purpose in life) and sociological (unemployment, birth of a child death of a loved one). In any case, the body's reaction will be the same regardless of the stressor.

Occupational cognitive failure (OCF) is a bunch of mistakes that happen at workplace (Allahyari, Rangi, Khosravi \& Zayeri 2011). The term cognitive failures were used by Broadbent et al (1982) which refers to minors slips which cause the normal course of proposed action either physical or mental, to be disrupted. Occupational Cognitive failures depict overall accountability towards recurrent gaps regarding cognitive control at workplace.

Many individuals are inclined to indulge cognitive failure mistakes more frequently than other persons. Occupational cognitive failures can be major concern as well as barricade to effectively accomplishing the routine work. The major elements which enhance susceptibility to occupational cognitive failures are not precisely defined. The healthy aged persons are linked with deterioration for certain kind of cognitive abilities like demanded recall (Hohman, Beason-Held, Lamar, \&Resnick, 2011).Cognitive failures are failures in perception, memory, and motor functioning, in which the action and intention don't match (Broadbent et al, 1982). Thus, occupational cognitive failure comprises several types of implementation lapses or the lapses in attention. The cognitive errors which occur at workplace environment called occupational cognitive failures.

Occupational cognitive failure is something that happens to every person in day to day functions, these may include perceptual failures or failures of actions and memory for example fail to recall people's names when you encounter them (Allahyari, Rangi, Khosravi \& Zayeri 2011). 
The common threat is a departure from the normal smooth flow of day to day functions and that the events of the day do not precede with the individuals intentions (Broadbent et al, 1982). The cognitive failure at workplace or occupational cognitive failures are reportedly related to many other constructs such as inattention, fatigue, work pressure, working environment unsuitability and work family conflicts (Allahyari, Rangi, Khosravi \& Zayeri 2011).

Emotional Climate includes emotionality revealed by employees, the image perceived by the incoming persons and numerous other stuffs that are observed at a glance. It is somewhat challenging to label a specific climate to a title. It is the feelings of individuals when someone walks into a new room (Evans, et.al.2009). Employees of an organization generally have maximum agreement in their opinions regarding climate.

There are several reasons for work stress, which are classified by researchers in different manners. Job stress and occupational cognitive failure are positively related with each other. The various laws which an individual have to obey andthe demand of high attention at workplace also hang onto someone in high stress (Kahn \& Byosiere 1992). There is positive relation with work demand, emotional demands and cognitive stress and due to that we experience cognitive failure.

Fairbrother and Warn (2003), reported the teamwork and environment have significant impacts on job satisfaction among naval officers. Kahn and Byosiere, (1992) stated in their model of job stress that employee's health and well-being are related to the different qualities of the work place environment.

The term occupational cognitive failures refer to negligible slips which leads to normal flow of actions disrupted at workplace. Occupational Cognitive failures depict overall accountability towards recurrent terrors in cognitive mechanism. Wallace and Chen (2005) devised a tool for workplace cognitive failures, and also reported negative relationships between safety-related behaviors and occupational cognitive failures (OCF).Studies evaluating the correlation between safety and occupational cognitive failures showed that cognitive failures predict the performance of persons at workplace (Wickens, Toplak,\& Wiesenthal, 2008).

Arthur and Barrett (2003) reported positive correlation between work place stress and cognitive failures $(\mathrm{CF})$. Distraction, inattention, and cognitive processing faults at workplace lead to accidents (Arthur \& 
Barrett, 2003). The same results were documented by O'hare, Wiggins and Morrison, (1994).

\section{Rationale of the Study}

The main purpose of the current study was to investigate the effects of emotional climate, job stress, and occupational cognitive failure among doctors. The study will be an addition to existing body of knowledge that how these variables are related and how these variables affect the employees. It will also add information on how to minimize the effects of stress. Moreover the current study will be a foundation for more research and beneficial for stakeholders. The cognitive traits like emotions and moods are a vital part of human life. These cognitive traits not only influence the person at individual level but also influence others at interactional level. In a recent investigation Batool et al (2018) explored the impact of cognitive failure on every day memory and insomnia. Emotional climate is shaped by the interactions among people at workplace (Schneider, Parkington, \&Buxton 1980). The emotional climate is considered relatively stable trait and influenced by the individuals / groups. In current era where the government as well as private owners are continuously trying to impose more and more responsibilities over the serving staff and the resulting work stress may have some type of impact on occupational cognitive failures. This study will help to know how work stress, emotional climate and occupational cognitive failure are related, and this study will help for awareness to overcome the social and domestic problems which are only due to these factors. The study aimed to examine the relationship between work stress, cognitive failure and emotional

climate. To find out more about the work stress, cognitive failure and emotional climate and how well these related to each other.

\section{Objectives}

1. To examine the relationship of emotional climate, work stress and occupational cognitive failure

2. To find out the effect of emotional climate and work stress on occupational cognitive failure

3. To examine the gender differences regarding emotional climate, work stress and occupational cognitive failure. 
4. To examine the differences of government and private doctors regarding emotional climate, work stress and occupational cognitive failure.

\section{Method}

\section{Participants}

The sample consisted of 150 MBBS and FCPS doctors who were working in private or government hospitals, of age range 25 to 55 years. Both male and female doctors were selected. The doctors who had personal clinic and working independently or the doctors who had been retired from service were excluded from the sample. Sample was taken conveniently from the various hospitals of Jhang and Faisalabad. Demographic variables used in this study were age, gender, institute, family system and residence.

\section{Measures}

Following scales were used in this study to measure the variables.

\section{Emotional Climate}

Emotional climate was measured by Emotional Climate scale developed by Yurtsever \& De Rivera (2010). It is a 7-point rating scale, consists of 28 items. Item no 2, 4, 6, 8, 10, 12, 14, 16, 18, 20, 22, 24, and 27 has reverse scoring.

\section{Work Stress Scale}

Work stress was measured by the work place stress scale developed by American institute of stress and adapted by Chohan (2013). Work place stress scale has eight items and it is a five point Likert scale. Higher scores indicate higher levels of occupational stress.

\section{Occupational Cognitive Failure Scale}

Occupational cognitive failure questionnaire by Allahyari, Rangi, Khosravi and Zayeri (2011) was used for occupational cognitive failure measurement. A five point Likert scale consists of 30 items, Cronbach alpha value of the scale reported by author is 0.96 . 


\section{Procedure}

In order to complete the requirement of the study informed consent was designed according to the ethics of research. Purpose of the study was explained to the participants and confidentiality of the research was ensured. The demographic information were gathered through demographic sheet. Keeping in view the objectives of the study, the appropriate statistical analysis was used through SPSS 24.

\section{Result}

This study was conducted to explore emotional climate, work stress and occupational cognitive failure among doctors. The data was analyzed by using t-test, correlation and regression to investigate the differences between groups, relationship between variables of the study and impact of independent variable on dependent variable respectively. The Hierarchical regression analysis was done where emotional climate, work stress and demographical variables were taken as independent variable and occupational cognitive failure was taken as dependent variable.

Table 1

Descriptive Data of Demographic Variables

\begin{tabular}{lll}
\hline Variables & Frequencies & Percentage \\
\hline Age & & \\
$25-40$ & 46 & 30.6 \\
$41-55$ & 104 & 69.33 \\
Birth order & & \\
$1-2$ & 92 & 61.3 \\
$3-5 \quad$ & 58 & 38.67 \\
Institution & & \\
$\quad$ Government & 83 & 55.3 \\
$\quad$ Private & 67 & 44.7 \\
Family System & & \\
$\quad$ Nuclear & 88 & 58.7 \\
$\quad$ Joint & 62 & 41.3 \\
Residence & & \\
\hline
\end{tabular}

PESHAWAR JOURNAL OF PSYCHOLOGY AND BEHAVIORAL SCIENCES, 2018, VOL. 4, NO. 2, 221-235 


\begin{tabular}{lcc}
\hline \multicolumn{1}{c}{ Rural } & 66 & 44.0 \\
$\quad$ Urban & 84 & 56.0 \\
Gender & & \\
Male & 74 & 49.3 \\
Female & 76 & 50.7 \\
\hline
\end{tabular}

Table 1 described the details of demographical picture of the sample. Around $30.6 \%$ of individuals were of age $25-40$ years while $60.4 \%$ of participants were of age 41-55 years. Government employees were 55.4\% and $44.6 \%$ were private employees. Around $58.6 \%$ of participants belonged to nuclear family system and $41.4 \%$ were from joint family system. It was found that $44 \%$ of participants were from rural background and $56 \%$ of individuals had urban background. From the sample $49.4 \%$ were male and around $50.6 \%$ were females doctors.

Table 2

Summary of Correlation Analysis: Relationship of Emotional Climate Work Stress and Occupational Cognitive Failure $(N=150)$

\begin{tabular}{clccc}
\hline & Variables & 1 & 2 & 3 \\
\hline 1 & Emotional & - & $.39^{* *}$ & $.56^{* *}$ \\
& $\begin{array}{l}\text { Climate } \\
2\end{array}$ & Work stress & - & $.26^{* *}$ \\
3 & $\begin{array}{l}\text { Occupational } \\
\text { Cognitive } \\
\text { failure }\end{array}$ & & - \\
\hline$P<, 0.01^{* *}$
\end{tabular}

The results of correlation analysis indicate that emotional climate is positively related with work stress and cognitive failure. Similarly, work stress has significantly positive relationship with cognitive failure. Emotional climate is positively correlated with work stress and occupational cognitive failure with $\mathrm{r} .395^{* *}$ and $r .56^{* *}$. On the other hand work stress and occupational cognitive failure was correlated with $r=$ $.26^{* *}$. 
Table 3

Comparison of Male and Female Doctors on Emotional Climate, Work Stress and Occupational Cognitive Failure by Independent Samples T-Test $(N=150)$.

\begin{tabular}{|c|c|c|c|c|c|c|c|c|c|}
\hline \multirow[t]{2}{*}{ Variables } & \multicolumn{2}{|c|}{$\begin{array}{c}\text { Male } \\
(n=74)\end{array}$} & \multicolumn{2}{|c|}{$\begin{array}{l}\text { Female } \\
(n=76)\end{array}$} & \multirow[b]{2}{*}{$t(148)$} & \multirow[b]{2}{*}{$p$} & \multicolumn{2}{|c|}{$95 \% C I$} & \multirow{2}{*}{$\frac{\text { Cohen's }}{d}$} \\
\hline & $M$ & $S D$ & $M$ & $S D$ & & & $L L$ & $U L$ & \\
\hline $\begin{array}{l}\text { Emotional } \\
\text { Climate }\end{array}$ & 117.33 & 17.03 & 119.88 & 13.64 & -1.01 & .31 & -7.51 & 2.43 & 0.16 \\
\hline Work Stress & 26.89 & 4.67 & 27.26 & 5.71 & -.43 & .66 & -2.05 & 1.31 & 0.07 \\
\hline $\begin{array}{l}\text { Occupational } \\
\text { Cognitive } \\
\text { failure }\end{array}$ & 109.95 & 18.00 & 105.93 & 13.55 & 1.54 & .12 & -1.13 & -9.18 & 0.25 \\
\hline
\end{tabular}

Independent samples t-test compute gender difference on Emotional climate, work stress and Occupational cognitive failure. The results revealed that Male and Female doctors have no significant difference on Emotional climate, work stress and Occupational cognitive failure (Table 3). To compare the Rural and urban doctors on Emotional climate, work stress and Occupational cognitive failure, independent sample T-test was done. No significant difference was found on this comparison (Table 4).

The results further revealed that Nuclear and Joint family doctors are significantly different on work stress, while no significant difference on emotional climate and Occupational cognitive failure was found. The analysis of mean showed that Nuclear family doctors had higher level of work stress as compared to Joint family doctors (Table 5).

Table 4

Comparison of Rural and Urban Doctors on Emotional Climate, Work Stress and Occupational Cognitive Failure by Independent Samples t-test $(N=150)$.

\begin{tabular}{|c|c|c|c|c|c|c|c|c|c|}
\hline \multirow[t]{2}{*}{ Variables } & \multicolumn{2}{|c|}{$\begin{array}{c}\text { Rural } \\
(n=66)\end{array}$} & \multicolumn{2}{|c|}{$\begin{array}{l}\text { Urban } \\
(n=86)\end{array}$} & \multirow[b]{2}{*}{$t(148)$} & \multirow[b]{2}{*}{$p$} & \multicolumn{2}{|c|}{$95 \% C I$} & \multirow{2}{*}{$\begin{array}{c}\text { Cohen's } \\
d\end{array}$} \\
\hline & $M$ & $S D$ & $M$ & $S D$ & & & $L L$ & $U L$ & \\
\hline $\begin{array}{l}\text { Emotional } \\
\text { Climate }\end{array}$ & 120.09 & 11.51 & 117.47 & 17.87 & 1.08 & .28 & -2.15 & 7.38 & 0.17 \\
\hline
\end{tabular}




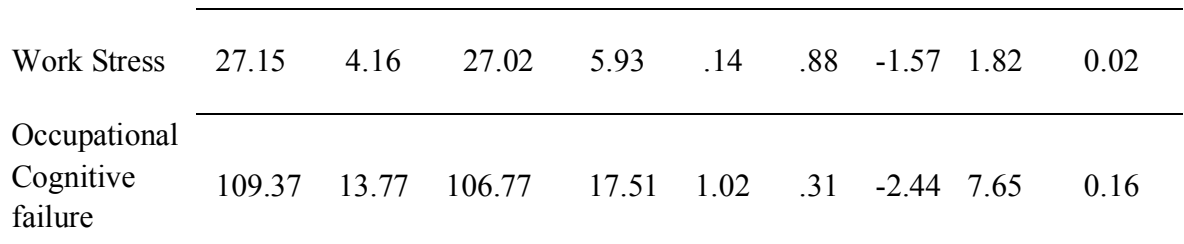

Table 5

Comparison of Nuclear and Joint Family Doctors on Emotional climate, Work Stress and Occupational Cognitive Failure by Independent Samples t-test $(N=150)$

\begin{tabular}{|c|c|c|c|c|c|c|c|c|c|}
\hline \multirow[t]{2}{*}{ Variables } & \multicolumn{2}{|c|}{$\begin{array}{l}\text { Nuclear Family } \\
\qquad(n=88)\end{array}$} & \multicolumn{2}{|c|}{$\begin{array}{l}\text { Joint Family } \\
\qquad(n=62)\end{array}$} & \multirow[b]{2}{*}{$t(148)$} & \multirow[b]{2}{*}{$p$} & \multicolumn{2}{|c|}{$95 \% C I$} & \multirow{2}{*}{$\begin{array}{c}\text { Cohen's } \\
d\end{array}$} \\
\hline & $M$ & $S D$ & $M$ & $S D$ & & & $L L$ & $U L$ & \\
\hline $\begin{array}{l}\text { Emotional } \\
\text { Climate }\end{array}$ & 119.86 & 14.78 & 116.87 & 16.22 & 1.17 & .24 & -2.05 & 8.03 & 0.19 \\
\hline Work Stress & 27.87 & 5.73 & 25.95 & 4.15 & 2.38 & .01 & .32 & 3.51 & 0.38 \\
\hline $\begin{array}{l}\text { Occupational } \\
\text { Cognitive } \\
\text { failure }\end{array}$ & 107.36 & 15.19 & 108.70 & 17.21 & -.50 & .61 & -6.59 & 3.90 & 0.08 \\
\hline
\end{tabular}

Table 6

Comparison of Government and Private Doctors on Emotional Climate, Work Stress and Occupational Cognitive Failure by Independent Samples t-test $(N=150)$

\begin{tabular}{|c|c|c|c|c|c|c|c|c|c|}
\hline \multirow[t]{2}{*}{ Variables } & \multicolumn{2}{|c|}{$\begin{array}{l}\text { Government } \\
\quad(n=83)\end{array}$} & \multicolumn{2}{|c|}{$\begin{array}{l}\text { Private } \\
(n=67)\end{array}$} & \multirow[b]{2}{*}{$t(148)$} & \multirow[b]{2}{*}{$P$} & \multicolumn{2}{|c|}{$95 \% C I$} & Cohen's \\
\hline & $M$ & $S D$ & $M$ & $S D$ & & & $L L$ & $U L$ & $d$ \\
\hline $\begin{array}{l}\text { Emotional } \\
\text { Climate }\end{array}$ & 119.13 & 17.07 & 118.00 & 13.16 &, 44 & .65 & -3.88 & 6.14 & 0.07 \\
\hline Work Stress & 23.16 & 3.21 & 23.79 & 3.56 & -.31 & .75 & -1.27 & .92 & 0.18 \\
\hline $\begin{array}{l}\text { Occupational } \\
\text { Cognitive } \\
\text { failure }\end{array}$ & 106.61 & 15.49 & 109.53 & 16.53 & -1.11 & .26 & -8.10 & 2.25 & 0.18 \\
\hline
\end{tabular}


Table 6 shows comparison of Govt. and Private Doctors on Emotional climate, work stress and Occupational cognitive failure no significant difference on Emotional climate, work stress and Occupational cognitive failure.

The results of hierarchical multiple regressions in which Emotional climate and work stress were independent variable and occupational cognitive failure as dependent variable in the first step. Step 1 produced a significant $R^{2}$ of .30 which means that independent variables collectively predicted $30 \%$ variance in occupational cognitive failure. In step 2 Demographic variables of gender, Residence, Family system and birth order of participants was entered as independent variables and occupational cognitive failure as dependent variable. Step 2 produced a significant $R^{2}$ of .36 which means that demographic variables collectively predicted $36 \%$ variance in occupational cognitive failure (Table 7).

Table 7

Summary of Hierarchical Regression Analysis: Effect of Emotional Climate, Work Stress and Demographic Characteristics on Occupational Cognitive Failure $(N=150)$

\begin{tabular}{lcc}
\hline Variables & \multicolumn{2}{c}{ Occupational Cognitive Failure } \\
\cline { 2 - 3 } & \multicolumn{1}{c}{$\Delta R^{2}$} & $B$ \\
\hline Step 1 & $.30^{* * *}$ & .54 \\
$\quad$ Emotional Climate & .05 \\
$\quad$ Work Stress & \\
Step 2 & -.12 \\
Gender of participants & $.36^{* *}$ & -.07 \\
Residence of & \\
participants & -.03 \\
Education of participants & .08 \\
Family System of & \\
participants & \\
Birth order of & -.20 \\
participants & \\
Total $R^{2}$ & \\
\hline Note: $\Delta R^{2}=\mathrm{R}$ Square change, $R^{2}=\mathrm{R}$ Square \\
$* p<.05, * * p<.01, * * * p<.001$
\end{tabular}




\section{Discussion}

The aim of current study was to examine the relationship between emotional climate, work stress and occupational cognitive failure. Firstly we hypothesized that Emotional climate, work stress and Occupational cognitive failure would have relationship and the findings of the current study supported this assumption. The results indicated that emotional climate, work stress and Occupational cognitive failure were related with each other. The findings of current study are in the line of the findings of Parkand Kim (2013). They concluded that work stress and Occupational cognitive failure are positively related with each other. Elfering, Grebner, \& Ebener, (2015) study also supported the findings of this study. This positive relation seems quite natural. The person who have work stress and emotionally charged climate may also have Occupational cognitive failures about daily tasks.

In second hypothesis we assumed that male and female doctors would be different on emotional climate, work stress and occupational cognitive failure. The findings of the current study depicted no significant difference regarding emotional climate, work stress and occupational cognitive failure. The findings of current study are supported by Arthur and Barrett (2003) work, they found no gender difference on emotional climate, work stress and occupational cognitive failure. This insignificant difference may be explained as both male and female doctors have same nature of job.

The third hypothesis was that government and private doctors were different on emotional climate, work stress and occupational cognitive failure. The findings depicted no significant difference regarding emotional climate, work stress, occupational cognitive failure in government and private doctors. These insignificant differences may also be interpreted due to same nature of job. Further it was assumed that emotional climate, work stress and demographic variables would likely to predict occupational cognitive failure. The results indicated that predictors collectively contributed in outcome variable. Emotional climate, work stress, Gender, residence, family system, education and birth order have significant contribution to the outcome variable occupational cognitive failure.

There was no specific research related to the predictors of the occupational cognitive failures however few previously conducted studies partially supported the result (Wadsworth, Simpson, Moss, and Smith, 2003; and Broadbent, Cooper, FitzGerald, and Parkes, 1982). Common sense and logic support our findings. Emotional climate and work stress 
has thirty percent contribution in occupational cognitive failure. If the environment will emotionally charge and employees would have work stress then surely they will be prone for cognitive errors at workplace.

\section{Conclusion}

The results concluded that emotional climate, work stress and occupational cognitive failure are significantly positively correlated with each other. Male and Female doctors experience same level of emotional climate, work stress and occupational cognitive failure. Similarly government and private doctors are equal on the level of emotional climate, work stress and occupational cognitive failure. The Organizations like hospitals must focus on the role of doctors if they inclined to prevent negative safety behaviors.

\section{Suggestions and limitations of the study}

The sample used for this study was taken from only two cities i.e. Jhang and Faisalabad doctors, sample from other cities should be included to generalize the results. The job level can also have significant impact on work stress and cognitive failure. Future researcher should also include participants from different level of jobs to study the effects of occupational cognitive failure among individuals working on different levels. These phenomenon should also be explored in people working on other jobs like clerks, engineers, professors.

\section{References}

Allahyari, T., Rangi, N. H., Khosravi, Y., \&Zayeri, F. (2011). Development and evaluation of a new questionnaire for rating of cognitive failures at work. International journal of occupational hygiene, 3(1), 6-11.

Arthur Jr, W., Bell, S. T., Villado, A. J., \&Doverspike, D. (2006). The use of person-organization fit in employment decision making: an assessment of its criterion-related validity. Journal of applied psychology, 91(4), 786-801.

Batool, I., Afzal, N., Khakwani, M., \& Khan, F. (2018) A Study of Cognitive Failures, Perceived Stress and Everyday Memory among Insomnia Patients. Isra Medical Journal, 10(4), 207-211. 
Berggren, N., Hutton, S., \&Derakshan, N. (2011). The effects of self-report cognitive failures and cognitive load on anti-saccade performance. Frontiers in psychology, 2, 280,1-5.

Broadbent, D. E., Cooper, P. F., FitzGerald, P., \& Parkes, K. R. (1982). The cognitive failures questionnaire (CFQ) and its correlates. British journal of clinical psychology, 21(1), 1-16.

Chohan,F. (2013) unpublished thesis, University of Punjab, Pakistan.

Cox, T., Oliver, A., Rial-González, E., Tomás, J. M., Griffiths, A., \& Thompson, L. (2006). The development of a Spanish language version of the Worn Out Scale of the General Well-Being Questionnaire (GWBQ). The Spanish Journal of Psychology, 9(1), 94-102.

Deniz, N., Noyan, A., \& Ertosun, Ö. G. (2015). Linking person-job fit to job stress: The mediating effect of perceived person-organization fit. Procedia-Social and Behavioral Sciences, 207, 369-376.

De Rivera, J., \& Páez, D. (2007). Emotional climate, human security, and cultures of peace. Journal of Social Issues, 63(2), 233-253.

Elfering, A., Grebner, S., \& Ebener, C. (2015). Workflow interruptions, cognitive failure and near-accidents in health care. Psychology, health \& medicine, 20(2), 139-147.

Evans, I. M., Harvey, S. T., Buckley, L., \& Yan, E. (2009). Differentiating classroom climate concepts: Academic, management, and emotional environments. Kötuitui: New Zealand Journal of Social Sciences Online, 4(2), 131-146.

Fairbrother, K., \& Warn, J. (2003). Workplace dimensions, stress and job satisfaction. Journal of managerial psychology, 18(1), 8-21.

Greenberg, J. S. (1990). Comprehensive Stress Management (3rd Ed.). Dubuque, IA. : Brown \& Benchmark Publishers.

Hohman, T. J., Beason-Held, L. L., Lamar, M., \& Resnick, S. M. (2011). Subjective cognitive complaints and longitudinal changes in memory and brain function. Neuropsychology, 25(1), 125-130.

Holmlund-Rytkönen, M., \&Strandvik, T. (2005). Stress in business relationships. Journal of Business \& Industrial Marketing, 20(1), $12-22$.

Kahn, R.L. \& Byosiere, P. (1992). Stress in organizations. In M.D. Dunnette \& L.M. Hough (eds) Handbook of Industrial and Organizational Psychology, vol. 3 Palo Alto, CA: Consulting Psychologists Press, pp. 571-650. 
Koys, D. J., \& DeCotiis, T. A. (1991). Inductive measures of psychological climate. Human relations, 44(3), 265-285.

O'Hare, D., Wiggins, M., Batt, R., \& Morrison, D. (1994). Cognitive failure analysis for aircraft accident investigation. Ergonomics, 37(11), 1855-1869.

Park, Y. M., \& Kim, S. Y. (2013). Impacts of job stress and cognitive failure on patient safety incidents among hospital nurses. Safety and health at work, 4(4), 210-215.

Schneider, B., Parkington, J. J., \& Buxton, V. M. (1980). Employee and customer perceptions of service in banks. Administrative science quarterly, 252-267.

Turner, J. H. (2007). Human emotions: A sociological theory. Routledge.

Wadsworth, E. J. K., Simpson, S. A., Moss, S. C., \& Smith, A. P. (2003). The Bristol Stress and Health Study: accidents, minor injuries and cognitive failures at work. Occupational Medicine, 53(6), 392-397.

Wallace, J. C., \& Chen, G. (2005). Development and validation of a work-specific measure of cognitive failure: Implications for occupational safety. Journal of Occupational and Organizational Psychology, 78(4), 615-632.

Wickens, C. M., Toplak, M. E., \& Wiesenthal, D. L. (2008). Cognitive failures as predictors of driving errors, lapses, and violations. Accident Analysis \& Prevention, 40(3), 1223-1233.

Yurtsever, G., \& de Rivera, J. (2010). Measuring the emotional climate of an organization. Perceptual and motor skills, 110(2), 501-516 